\title{
Study on Acoustic Performance of a Water Muffler for Gear Pump
}

\author{
Tao Du \\ Institute of Process Equipment, Zhejiang University, Road 38, Hangzhou, 310027, China. \\ A. O. Smith (China) Water Heater Co., Ltd., 336 Yaoxin Avenue, NETDZ, Nanjing, 210038, China.
}

\author{
Ning Chu \\ Institute of Process Equipment, Zhejiang University, Road 38, Hangzhou, 310027, China. \\ Engineering department, Swiss federal Institute of Technology in Lausanne (EPFL), 1015, Switzerland. \\ Linlin Cao, Tiancheng Miao and Dazhuan Wu \\ Institute of Process Equipment, Zhejiang University, Road 38, Hangzhou, 310027, China.
}

\begin{abstract}
(Received 30 August 2015; accepted 30 June 2016)
A water muffler is used for the noise control of a hydraulic pipeline with an external gear pump. An experimental system is established to investigate the acoustic performance of the water muffler, in which the gear pump is utilized as the sound source and power supply. Comparisons between the experimental results of the reference tube, rubber tube, and water mufflers with different inner structures have been made. Numerical simulations on the rubber tube and different water mufflers with various inner structures have been conducted. Simulation results have been compared with the experimental results. These comparison results show that the rubber tube with a compliant wall substantially contributes to the reduction of the noise generated by the gear pump, especially at the high frequency band and relatively low rotate speed of the gear pump. The water muffler results in the enhancement of the noise reduction effect on the rubber tube. With the speed of the gear pump increasing from $1172 \mathrm{r} / \mathrm{min}$ to $2344 \mathrm{r} / \mathrm{min}$, the effect of the noise reduction becomes much weaker, since the flow-induced noise gets more intensified. For the rubber tube, in particular, the sound pressure level gets close to that of the reference tube at the speed of $2344 \mathrm{r} / \mathrm{min}$. Moreover, it has been proven by another important experimental result that the length of the inner structure can play a critical role to the flow noise generation.
\end{abstract}

\section{INTRODUCTION}

As one of the most widely used pumps for decades, the gear pump has proved to be very favorable to industries, owing to its simple mechanism, high delivery pressure, compact construction, and high reliability. However, they are usually accompanied by characteristic side effects that tend to cause much louder noise and stronger vibration than other types of positive displacement pumps. ${ }^{1,2}$ The noise and vibration generated by gear pumps can affect the downstream equipment and working environment through connected pipelines and flowing fluid, and this phenomenon could substantially harm the precision of system control, and even destroy working stability of the downstream equipment. Thus, it is highly necessary to effectively control the noise and vibration.

There are mainly two sources of noises, sharing the same fundamental frequency: the pressure ripple created by the variation in delivery flow from the pump and the periodic variation of gear meshing force. If the pressure ripple can be weakened, the flow-induced noise will be consequently reduced, so that there will be potential benefits for a longer component life, and it will reduce structure-borne noise from the pump. ${ }^{3-5}$ Iyoi and Ishimura have indicated that it is not possible to fabricate external gear pumps without delivery fluctuation, but it is feasible to minimize the pressure ripple, and consequently fluctuations, by adopting a more precise design of the pump. ${ }^{6}$

Hydraulic performance of the rotary gear pump mainly depends on the following factors: the design of inlet and discharge openings, side and tip clearance, gear shapes, and tooth profiles. Huang and Lian have investigated numerically how several gear parameters (including teeth number and pressure angle) can help in reducing flow fluctuations. ${ }^{1}$ Mitome and Seki have shown that noise and vibration of a gear pump can be reduced by better design of tooth profile. ${ }^{7}$ These methods are the key issues for the advanced design of new gear pumps. However, further measurements should be taken into consideration in order to effectively control the propagating of noise and vibration and to avoid damage to the downstream equipment.

In previous studies, different kinds of water mufflers/silencers are used to attenuate the noise and vibration in hydraulic pipelines. Strunk has investigated the insertion loss for a specific type of side branch resonator, called a cross-loop attenuator, and has identified the design parameters which are critical to insertion loss for a piston pump. ${ }^{8}$ Dodson et al. have tested three types of quarter wavelength side-branch resonators (in-line, flexible side-branch, and rigid side-branch, respectively) in an industrial-scale hydraulic system. ${ }^{9}$ All three types were found to obtain positive noise reduction characteristics with maximum IL from 10 to $20 \mathrm{~dB}$ at the pump's pistonpassage frequency. Kojima and Ichiyanagi have presented the development of two types of multiple volume resonators called a "variable resonance-mode type side-branch resonator" and a "multi-degree-of-freedom type Helmholtz resonator."10 Mikota has proposed a novel, compact pulsation compensator to reduce pressure pulsations in hydraulic systems. ${ }^{11}$ Earnhart and Cunefare have introduced a Helmholtz resonator design based on a compliant, voided urethane lining, and it would 


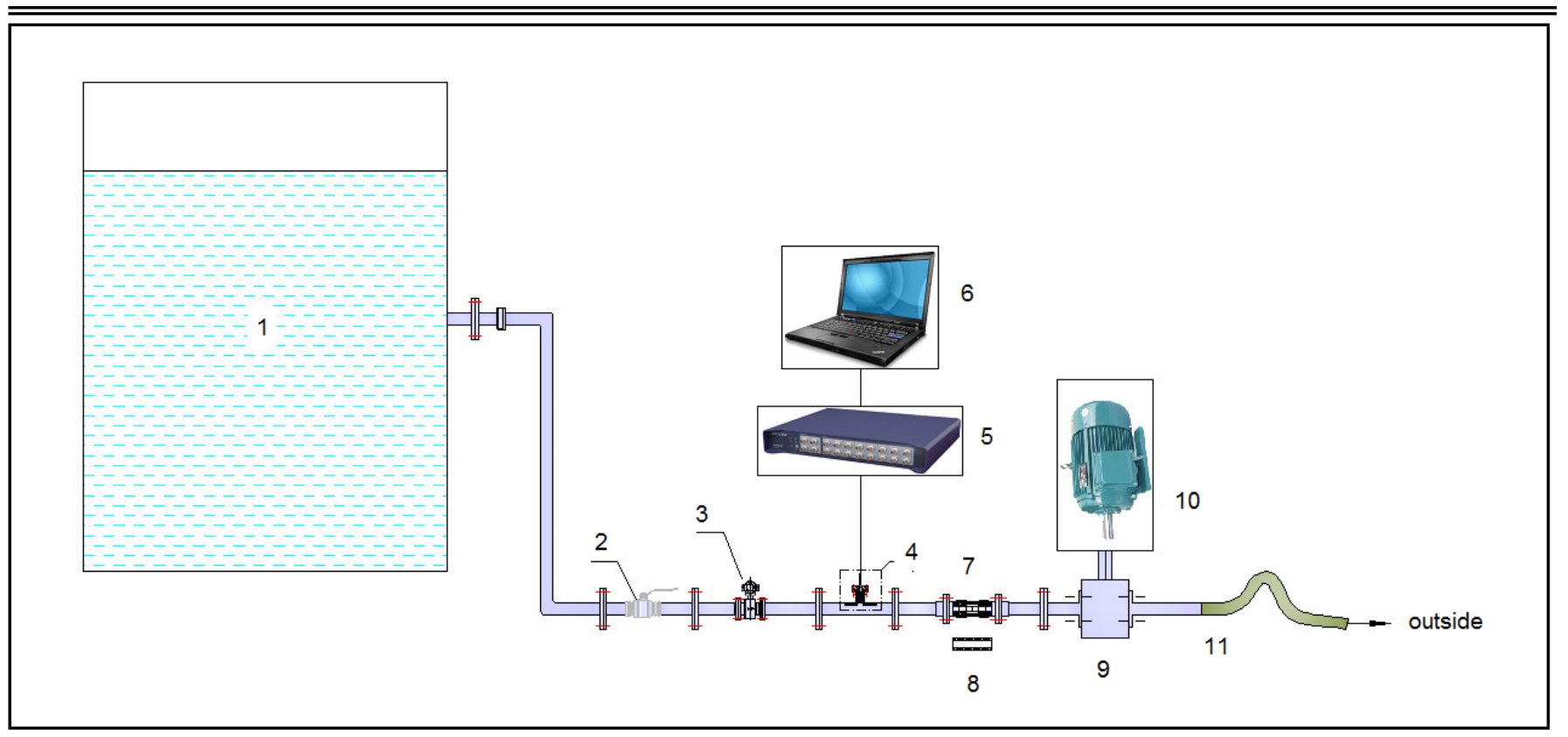

Figure 1. Schematic of the test arrangement: 1 - Water reservoir, 2 - Valve, 3 - Flow meter, 4 - Hydrophone, 5 - Data collector and analyzer, 6 - Computer, 7 - Test sample, 8 - Reference tube, 9 - Pump, 10 - Electrical motor, 11 - Hose tube.

help to increase the apparent volume of the device so that much smaller physical sizes of the device for the same resonance frequency could be achieved. ${ }^{12}$

Most of the water mufflers presented in previous studies can only work well in the cases of single frequency or narrow frequency bands, and these mufflers always confront assembling difficulties due to the oversized structure against limited installation spaces. Moreover, steel tubes in the major parts of water muffler are so rigid that the vibration could easily propagate along the tube.

In our previous studies, a water muffler based on the Kevlar reinforced rubber tube and inner noise attenuating structure was proposed to achieve a good vibration damping as well as better hydrodynamic noise performance. ${ }^{13}$ Experimental studies were conducted on the acoustic performance of the water muffler under stationary state and low flow rate. It was shown that the proposed muffler can significantly reduce noises in wide bands. The experimental condition allowed for studying the mechanism of the noise reduction effect, but it was not sufficient to reflect the noise reduction of the water muffler under practical condition. A loudspeaker driven by a noise generator was used as the sound source, but this source differs from the real noise source, not mention to the mechanism of noise generation. This is because that noise generated by a pump is principally excited by the fluid pulsation, rather than the vibration of the vibrating diaphragm in a loudspeaker. In addition, the flow velocity was limited to a small value due to the function of the experimental apparatus, which was unable to truly reflect the effect of the flow-induced noise for real application.

In this present study, the acoustic performance of proposed water muffler was tested with an external gear pump. The acoustic characteristics of the gear pump were firstly measured at three different speeds by using a frequency converter control. The overall noise level was higher than that generated by a loudspeaker. The noise characteristic of the gear pump is presented. Then comparison among the acoustic performances of the reference tube, rubber tube and, water muffler is made at those three speeds. It can be observed that flow-induced noise, which increases with increasing flow-velocity did affect the acoustic performances of rubber tube and water muffler. Fi- nally, the acoustic performances of water mufflers with different inner structures at the three speeds are compared. Numerical simulations of acoustic performances of the rubber tube and water muffler at three speeds, as well as water mufflers with different inner structures at one of three speeds are conducted in commercial software. Comparisons between the simulation and experimental results have been made and discussed.

\section{EXPERIMENTAL SETUP}

The experimental apparatus is schematically shown in Fig. 1, and the photograph of the test arrangement is given in Fig. 2.

As depicted in Fig. 1, a water reservoir was used as the water supply with the size of $3 \mathrm{~m} \times 1.5 \mathrm{~m} \times 2 \mathrm{~m}$ and the water depth of $1.2 \mathrm{~m}$. A hydrophone flush mounted on the tube, is arranged at horizontally $0.15 \mathrm{~m}$ away from the test sample in order to acquire the downstream signal. The hydrophone is a Reson product type TC4013, whose usable frequency ranges from $1 \mathrm{~Hz}$ to $170 \mathrm{kHz}$. Sound pressure signals were recorded continuously for $15 \mathrm{~s}$ by using an Econ AVANT MI-7016 data collector and analyzer. One-third octave spectrogram and frequency spectrogram are calculated simultaneously and averaged over $15 \mathrm{~s}$. The reference pressure is $1 \mu \mathrm{Pa}$ for data processing in all tests.

Three kinds of specimens were tested in the experiments, namely, a reference tube, a rubber tube, and the water muffler. The reference tube was steel with the same length and inner diameter as the water mufflers. The inner diameter of all test tubes is $25 \mathrm{~mm}$.

The structure of the water muffler is depicted in Fig. 3. It can be seen that the water muffler was composed of two main detachable parts, namely, the Kevlar reinforced rubber tube (simplified as the rubber tube in following discussion) and the inner noise attenuating structure (simplified as the inner structure).

The noise reduction principle in the rubber tube is based on the dissipative muffler with compliant wall. The sound pressure and particle velocity during sound propagating in tubes with compliant walls (in cylindrical polar coordinate system for cylindrical tubes) are: ${ }^{14}$ 


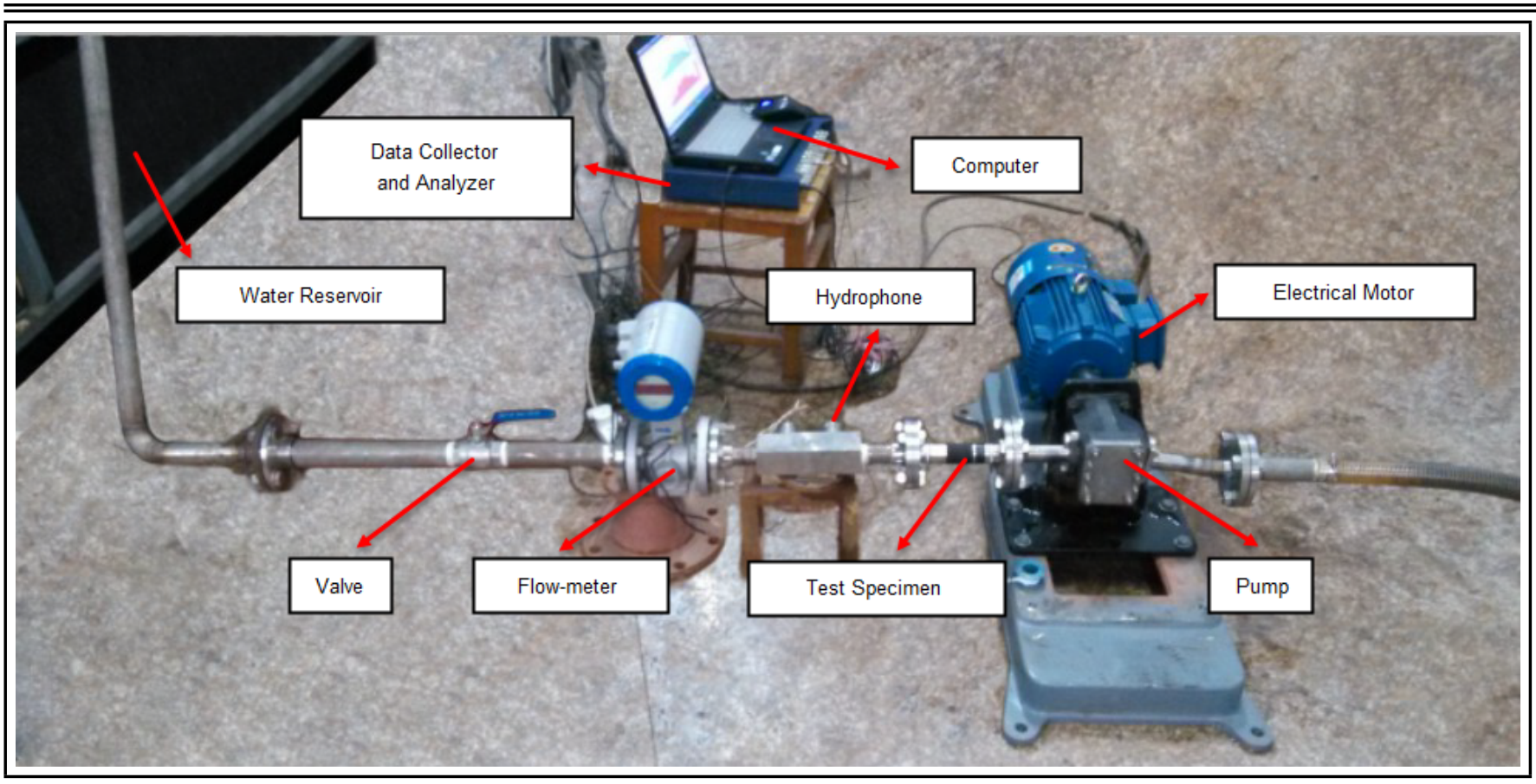

Figure 2. Photograph of the test arrangement.

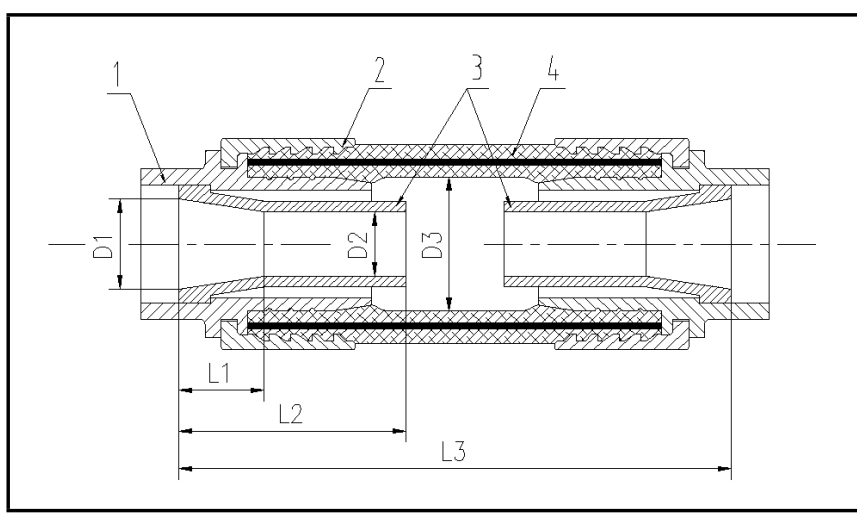

Figure 3. Structure of the water muffler: 1 - Metal core, 2 - Metal lock catch, 3 - Inner noise attenuation structure, 4 - Rubber tube.

$$
\begin{array}{r}
p(r, \theta, z, t)= \\
=\sum_{m=0}^{\infty} \sum_{n=0}^{\infty} J_{m}\left(k_{r, m, n} r\right) e^{j m \theta} e^{j \omega t}\left\{C_{1, m, n} e^{-j k_{z, m, n} z}+\right. \\
\left.+C_{2, m, n} e^{+j k_{z, m, n} z}\right\}
\end{array}
$$

where $k_{r, m, n}$ and $k_{z, m, n}$ as the transmission wave number for the $(m, n)$ mode in radius direction and axial direction respectively. Tubes with compliant walls (that is, with complex wall impedance) resulted in the complex value of axial direction wave number $k_{z}$. The imaginary component of $k_{z}$ would introduce attenuation in the axial direction.

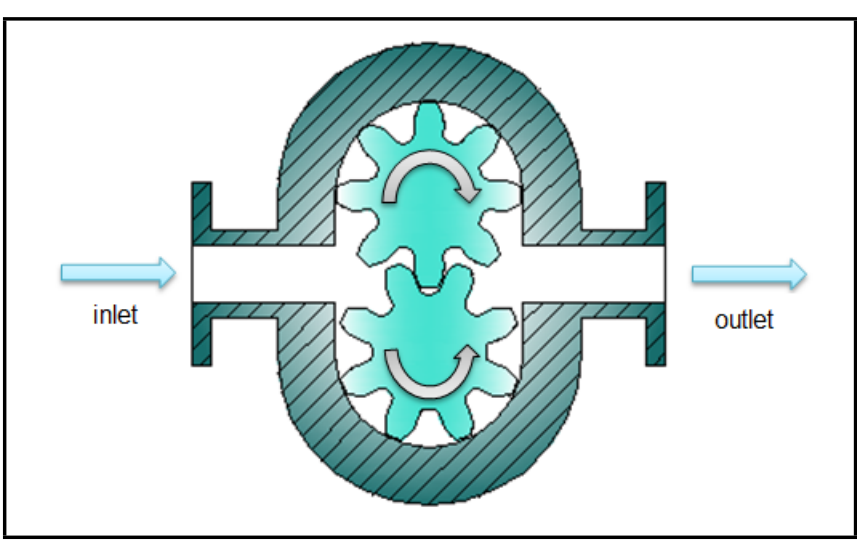

Figure 4. Schematic of the gear pump.

The inner structure is characterized by the combination of a conical tube and extended-tube resonators, which are typical reactive muffler structures. Since these structures would cause the mismatch of characteristic impedances, a great amount of the incident power will be reflected back to the source. ${ }^{14}$

The inner structures were symmetrically mounted at both sides of the water muffler. The parameters of the water muffler vital to the noise reduction are the ratio of the inner diameter of the inner structure to that of the rubber tube $R_{d}=D 2$ : $D 3$, and the ratio of the length of the inner structure to that of the rubber tube $R_{l}=L 2: L 3 . D 1, D 2, D 3, L 1, L 2$ and $L 3$ are schematically shown in Fig. 3. With $R_{d}$ kept constant, the influence of $R_{l}$ on the acoustic performance of the water muffler is studied by altering the length of the inner structure $L 2$. $R_{l}$ considered are $0.336,0.344,0.352,0.360$, and 0.368 , respectively.

Figure 4 shows a cross-sectional view taken through the gears of a typical gear pump. By means of frequency converter control, acoustic performances of the reference tube, rubber tube, and water mufflers with different inner structures are tested with the gear pump at three speeds (1172, 1758 and $2344 \mathrm{r} / \mathrm{min})$. The corresponding flow velocities are about $1.4,2.1$, and $2.8 \mathrm{~m} / \mathrm{s}$, respectively. The number of teeth in 


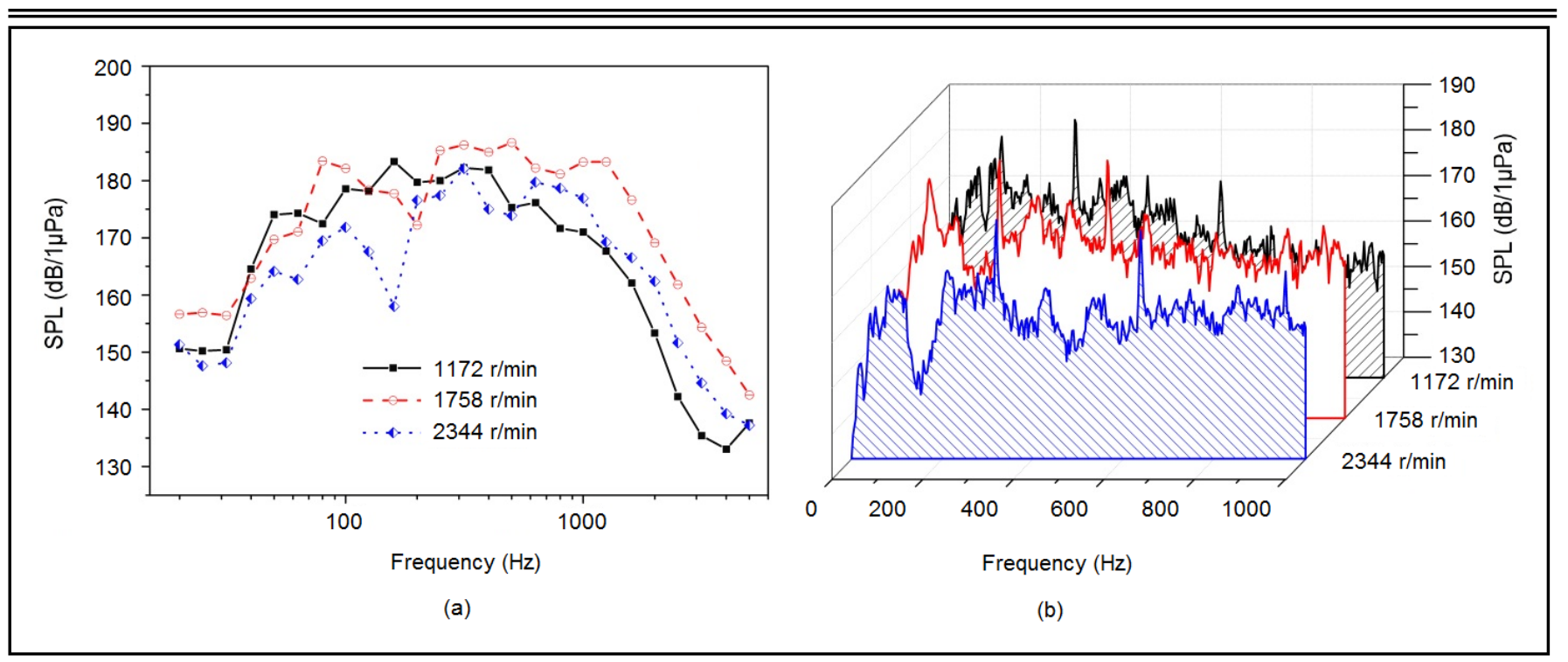

Figure 5. $S P L$ of the pump: (a) one-third octave spectrogram, (b) frequency spectrogram.

each wheel of the gear pump is $Z=8$, resulting in the operation fundamental frequencies as 156,234 , and $312 \mathrm{~Hz}$, respectively. The inlet of the pump is connected to the water reservoir and the outlet to the atmospheric through the pipes. Thus, the operation pressure is close to the atmospheric pressure.

\section{EXPERIMENTAL RESULTS}

\subsection{Acoustic Performance of the Gear Pump}

Sound pressure levels $(S P L)$ of the gear pump measured with the reference tube at three speeds are depicted in Fig. 5. Figure 5(a) shows the one-third octave spectrogram at the frequency band from $20 \mathrm{~Hz} \sim 5000 \mathrm{~Hz}$. Details in the frequency band lower than $1000 \mathrm{~Hz}$ can be seen from the frequency spectrogram in Fig. 5(b). It revealed that the overall noise level is high at all three speeds. The noise energy is concentrated at the frequency band from $100 \mathrm{~Hz}$ to $1000 \mathrm{~Hz}$. The fundamental frequencies and their second and third harmonics at different speeds are of significant strengths as shown in the frequency spectrogram. This implies that suppressing these harmonics can greatly improve acoustic performance of gear pump.

\subsection{Comparison of the Reference Tube, Rubber Tube and Water Muffler}

Experimental results on the reference tube, the rubber tube and the water muffler with $R_{l}=0.336$ at the three speeds are depicted in Fig. 6.

Insertion loss $(I L)$ is one of the widely used indicators to describe the performance of a muffler, and $I L$ is usually defined as the difference between the sound power level without any filter $\left(L_{W 1}\right)$ and that with the filter $\left(L_{W 2}\right) .{ }^{15-17}$ Symbolically,

$$
I L=L_{W 1}-L_{W 2}=10 \log \left(\frac{W_{1}}{W_{2}}\right) \quad(d B) .
$$

Normally, when the size and shape of the tube and the sound field distribution remains approximately unchanged, the insertion loss equals the difference between the sound pressure level without any filter $\left(L_{p 1}\right)$ and that with the filter $\left(L_{p 2}\right)$. That is,

$$
I L=L_{p 1}-L_{p 2} \quad(d B) .
$$

Insertion loss of the rubber tube and the water muffler at the three velocities from $20 \mathrm{~Hz}$ to $5000 \mathrm{~Hz}$ are depicted in Fig. 7.

The left three subfigures in Fig. 6 and Fig. 7 present the experimental results of $S P L$ and $I L$ at the three speeds, from which the noise suppression at the high frequency band could be seen for the rubber tube case. With the speed increasing from $1172 \mathrm{r} / \mathrm{min}$ to $2344 \mathrm{r} / \mathrm{min}$, the effective frequency band switches to a higher frequency range and the noise suppression effect turns to be weakened. Nevertheless, the muffler shows the relatively good acoustic performance through the entire frequency band considered.

From the three subfigures on the right in Fig. 6, it can be seen that the noise suppression effect of the rubber tube is rather limited at the fundamental frequency and its harmonics. In contrast, the muffler can distinctively reduce the peak values at these frequencies even at the high speed of $2344 \mathrm{r} / \mathrm{min}$. This implied that the water muffler can effectively reduce the fluid pulsation generated by the pump. For both the rubber tube and the muffler, the noise suppression effect turned to be weakened with the increase of speed especially at the low frequency band.

Noise reduction of the rubber tube is majorly contributed by its compliant wall as discussed in Section 2. The material of the rubber tube also absorbs sound energy particularly at the high-frequency band. ${ }^{18}$ Furthermore, when the gear pump operates at a relatively low speed, the structure of the rubber tube may lead to slight noise reduction due to the cross area change at the lock catch. The water muffler enhanced the noise reduction via the sound reflection effect induced by the shape of the inner structure and the resonant cavity formed by the combination of the rubber tube and the inner structure. This resistant structure is particularly effective to the low frequency band noise.

The flow-induced noise, which increases with flow velocity, makes the inherent noise reduction effect of the structure less distinctive at high speed. They are highly associated with the variation of flow area, at the location such as the connections and valves in the pipeline and the lock catch in the rubber tube. As a result, the sound pressure level of the rubber tube turned to be close to that of reference tube at the speed of $2344 \mathrm{r} / \mathrm{min}$.

Total sound pressure level is defined as the sound pressure level through the whole frequency band: 


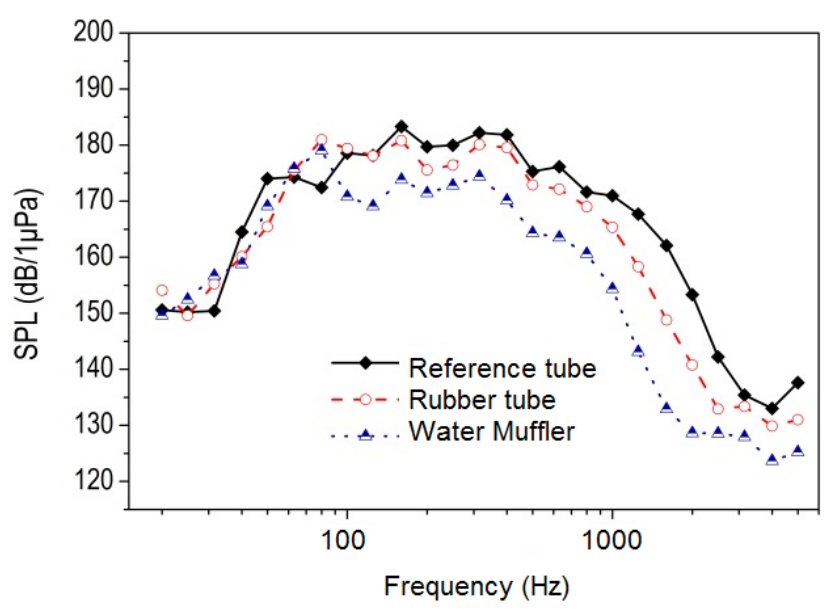

(a)

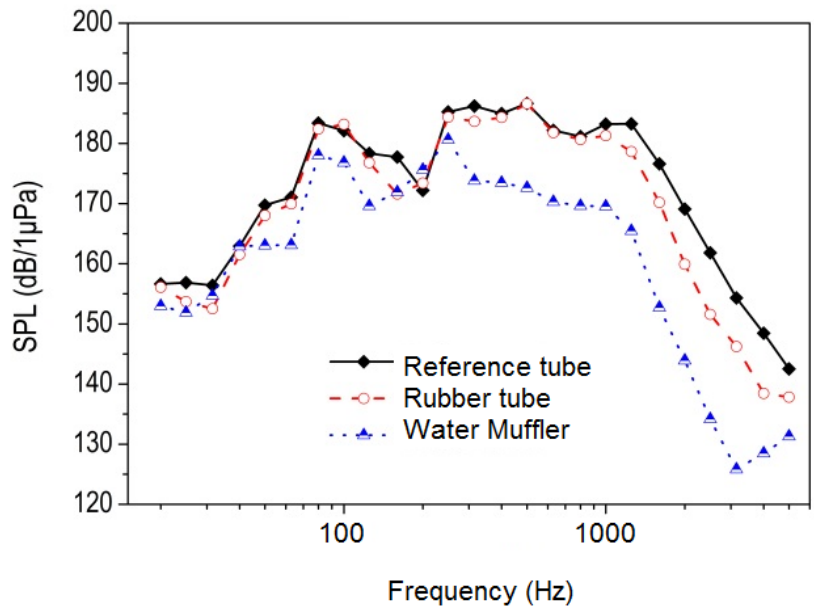

(c)

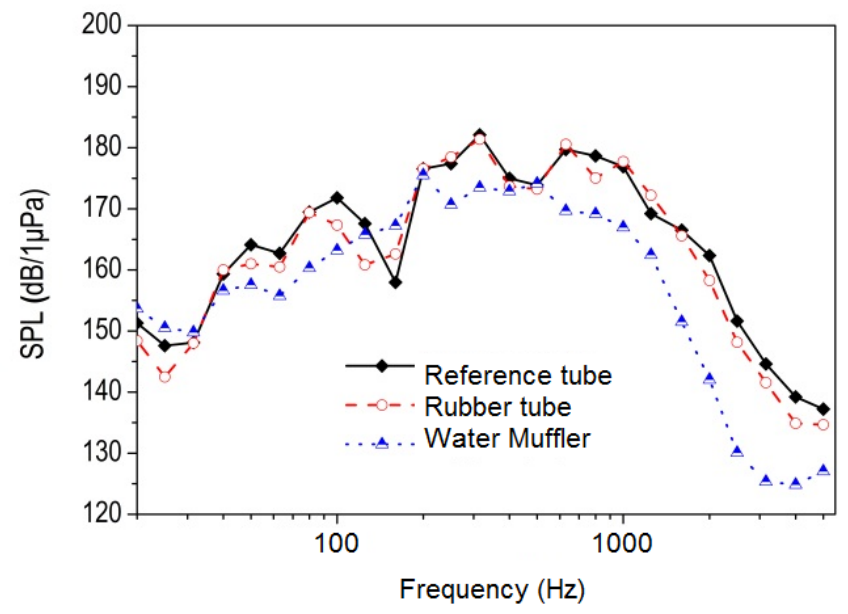

(e)

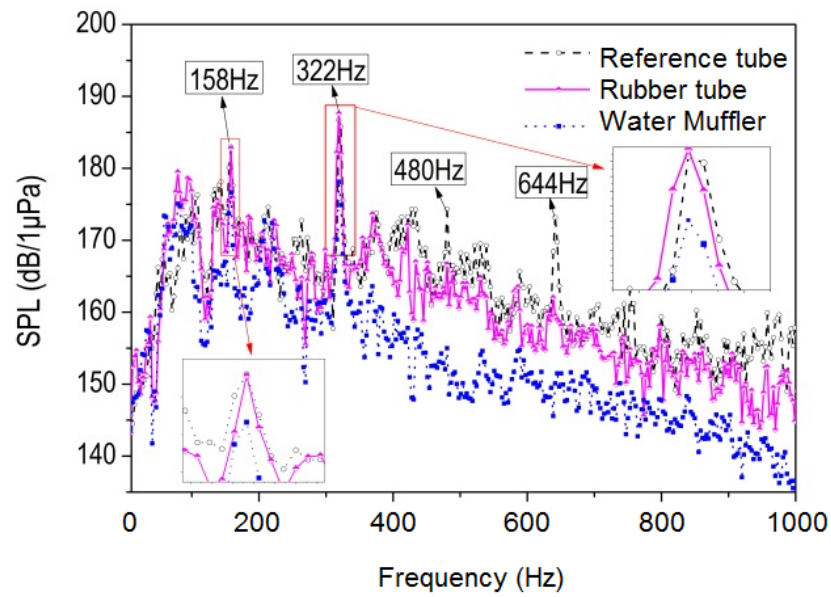

(b)

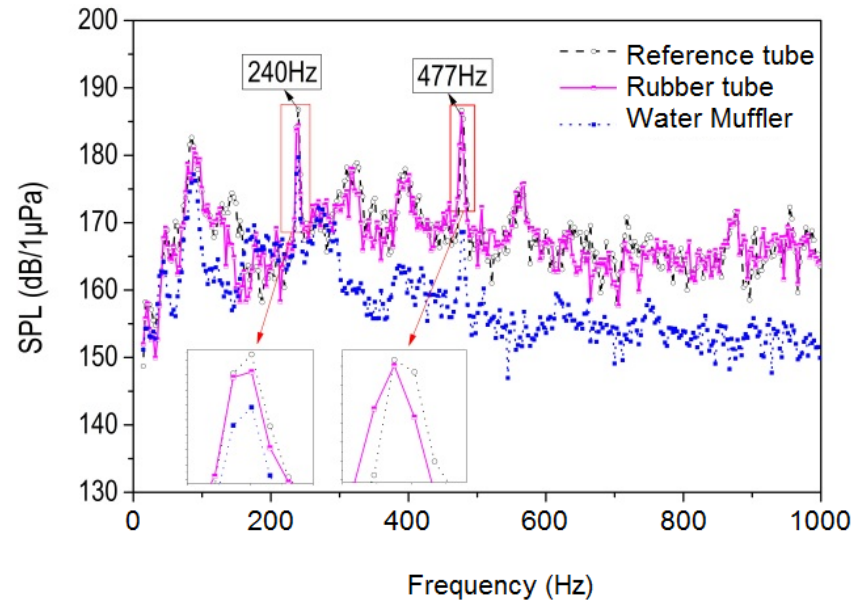

(d)

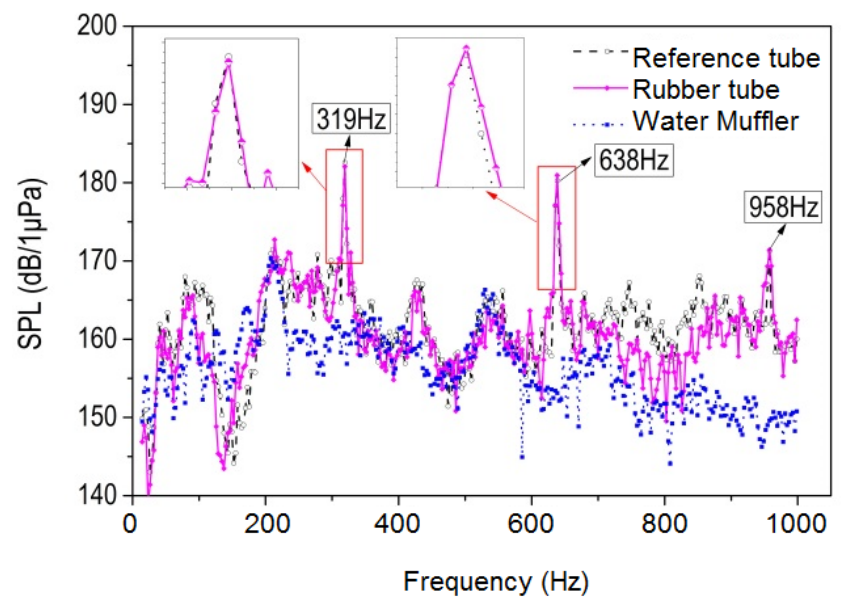

(f)

Figure 6. Test results on the reference tube, the rubber tube and the water muffler with $R_{l}=0.336$ at the three speeds: (a) 1172 r/min one-third octave spectrogram, (b) $1172 \mathrm{r} / \mathrm{min}$ frequency spectrogram, (c) $1758 \mathrm{r} / \mathrm{min}$ one-third octave spectrogram, (d) $1758 \mathrm{r} / \mathrm{min}$ frequency spectrogram, (e) $2344 \mathrm{r} / \mathrm{min}$ onethird octave spectrogram, (f) $2344 \mathrm{r} / \mathrm{min}$ frequency spectrogram.

$$
L_{p, \text { total }}=10 \times \log _{10}\left(\sum_{i=1}^{N} 10^{\left(\frac{L_{p i}}{10}\right)}\right) \quad(d B) ;
$$

where $L_{p, t o t a l}$ is the total sound pressure level and $L_{p i}$ is the sound pressure level of each frequency band. Total insertion loss $(T I L)$ is defined as the difference between the $L_{p, t o t a l}$ of the specimen and that of the reference tube. $L_{p, t o t a l}$ and TIL of the test specimens at frequency band from $20 \mathrm{~Hz}$ to $5000 \mathrm{~Hz}$ are listed in Table 1.

It can be seen from Table 1 that the noise reduction effect of the rubber tube is rather limited, especially at a relatively high velocity. Nevertheless, the noise reduction offered by the water muffler was found to be more than $5 \mathrm{~dB}$ at all three speeds, indicating its distinctive capability to reduce the noise generated by the equipment like the gear pump. 


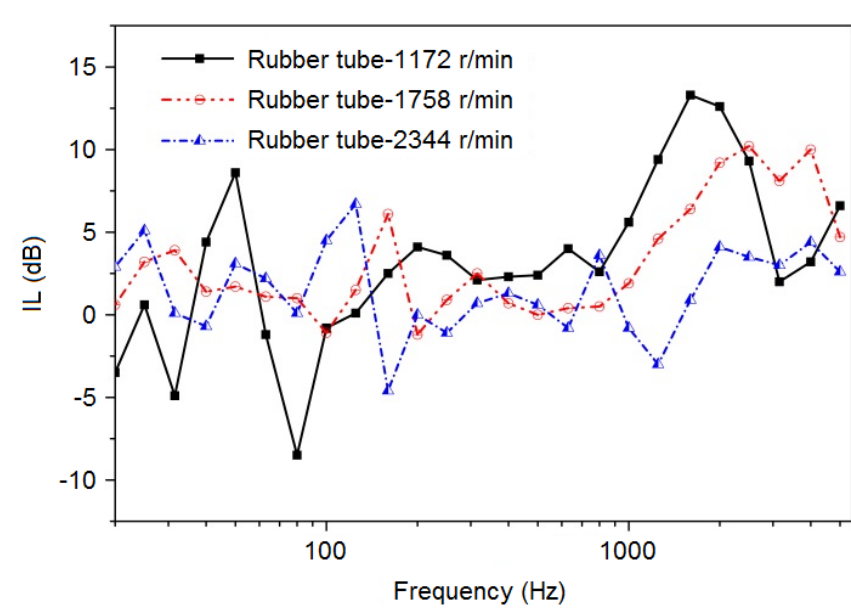

(a)

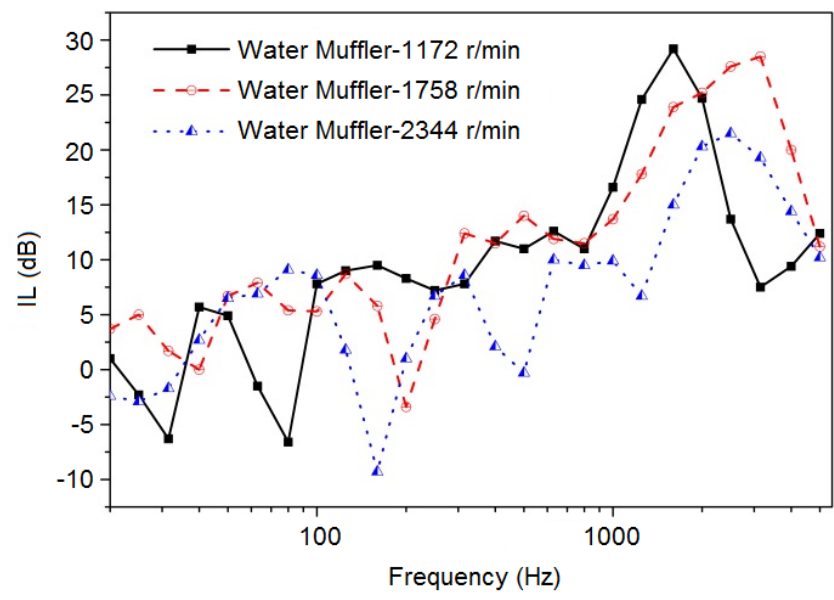

(b)

Figure 7. $I L$ of: (a) the rubber tube, and (b) the water muffler.

Table 1. $L_{p, \text { total }}$ and $T I L$ of the test specimens.

\begin{tabular}{|c|c|c|c|c|c|c|}
\hline & \multicolumn{2}{|c|}{ Reference Tube } & \multicolumn{2}{c|}{ Rubber Tube } & \multicolumn{2}{c|}{ Water Muffler } \\
\hline Revolving Speed & $L_{p, \text { total }}(\mathrm{dB})$ & $T I L(\mathrm{~dB})$ & $L_{p, \text { total }}(\mathrm{dB})$ & $T I L(\mathrm{~dB})$ & $L_{p, \text { total }}(\mathrm{dB})$ & $T I L(\mathrm{~dB})$ \\
\hline $1172 \mathrm{r} / \mathrm{min}$ & 190.2 & - & 188.8 & 1.4 & 184.0 & 6.2 \\
\hline $1758 \mathrm{r} / \mathrm{min}$ & 194.6 & - & 193.4 & 1.2 & 185.9 & 8.7 \\
\hline $2344 \mathrm{r} / \mathrm{min}$ & 187.7 & - & 187.3 & 0.4 & 181.8 & 5.9 \\
\hline
\end{tabular}

\subsection{Comparison of Water Mufflers with Different Inner Structures}

Test results of water mufflers with different inner structures at three speeds are plotted in Fig. 8. More details at the frequency band lower than $500 \mathrm{~Hz}$ can be seen from the frequency spectrogram in the subfigures at the right hand.

Generally, the variation of ratio $R_{l}$ would result in different resonant cavities, and different noise reduction of the water mufflers. Moreover, the internal flow properties of the muffler are also affected by $R_{l}$, especially the flow-induced noise, which increases with flow speed. The water mufflers with different inner structures cannot significantly distinguish from each other in the noise reduction, since they only show slight difference in the inner structure length. At the speed of $1172 \mathrm{r} / \mathrm{min}$, the acoustic performances of three mufflers are close to each other except for some points between $100 \mathrm{~Hz}$ and $300 \mathrm{~Hz}$. At speeds of $1758 \mathrm{r} / \mathrm{min}$ and $2344 \mathrm{r} / \mathrm{min}, S P L \mathrm{~s}$ of three mufflers with smaller $R_{l}(0.336,0.344$ and 0.352$)$ are close to each other, while the other two mufflers present rather close and relatively lower $S P L$ s compared to the former three ones. This is probably because that it is easier for the flow to go through the muffler with longer inner structure. Accordingly, the flow-induced noise will be lower. In general, the water mufflers with $R_{l}$ of 0.360 and 0.368 have better performances.

\section{NUMERICAL SIMULATION}

The acoustic performance of the rubber tube and the mufflers were simulated in the commercial software LMS Virtual Lab with its acoustic harmonic FEM analysis module. Due to the limitation of computational resources, it was unrealistic to exhaustively model the whole system. Therefore, for the computation presented in this article, the experimental system is simplified as the combination of the test sample and two extended test tubes with reasonable sizes. The effect of other parts of the system was considered, according to the boundary conditions.
Table 2. Quantities of computation grids.

\begin{tabular}{|c|c|}
\hline Grid size & Grid quantity \\
\hline $2.5 \mathrm{~mm}$ & 118905 \\
\hline $2.3 \mathrm{~mm}$ & 142364 \\
\hline $2.0 \mathrm{~mm}$ & 209648 \\
\hline $1.8 \mathrm{~mm}$ & 324423 \\
\hline $1.5 \mathrm{~mm}$ & 465788 \\
\hline
\end{tabular}

\subsection{Computational Grid}

To evaluate the grid independence as well as the solution validity, several sets of grids with different grid quantities were built in the computational domain through adjusting the grid size. One of these sets is shown in Fig. 9. Grid quantities are listed in Table 2. SPLs at the outlet computed with different grid sizes are depicted in Fig. 10(a). And the SPLs at $1000 \mathrm{~Hz}$ are compared in Fig. 10(b). The numerical solutions and acoustic performances offered by the grid sets with more than 200,000 grid quantities have been proven to be rather close to each other, therefore, the option of grid set with 209,648 elements is adopted in terms of feasibility consideration.

\subsection{Boundary Conditions}

To offer a proper sound source close to that in practical application, the acoustic measurements for the reference tube at corresponding speed were employed as the sound source model in the simulations of the rubber tube and water muffler. A monitor point was setup at the location where the hydrophone is mounted in experiments, and the rubber wall and the flow outlet were expressed by sound absorbent panels with adjustable impedance. According to the discussion in Section 2, impedances of the rubber wall in the rubber tube and the water muffler should be a complex number. As the system impedance was kept unknown, the reasonable impedance of the rubber wall was obtained according to the trial and error method in the previous article of the authors, as listed in Table $3 .{ }^{13}$ The impedance of the outlet was determined to be 


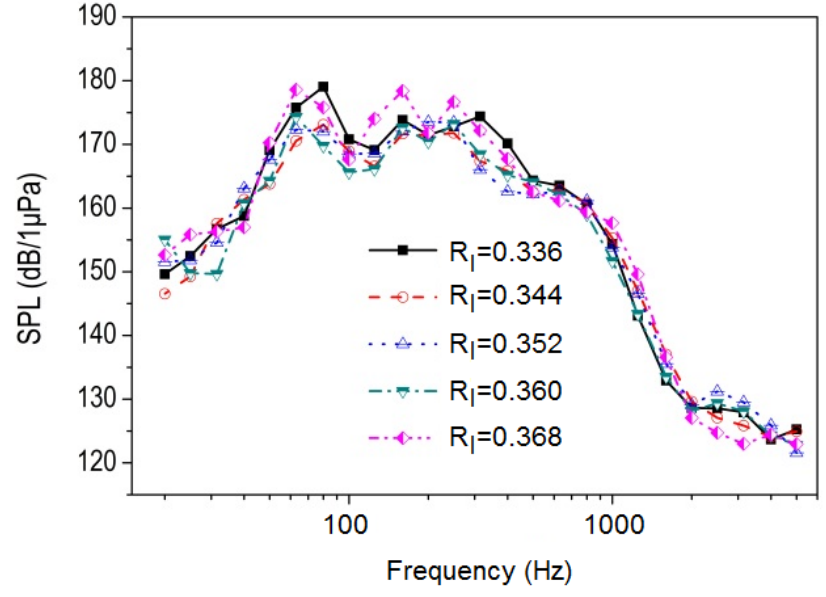

(a)

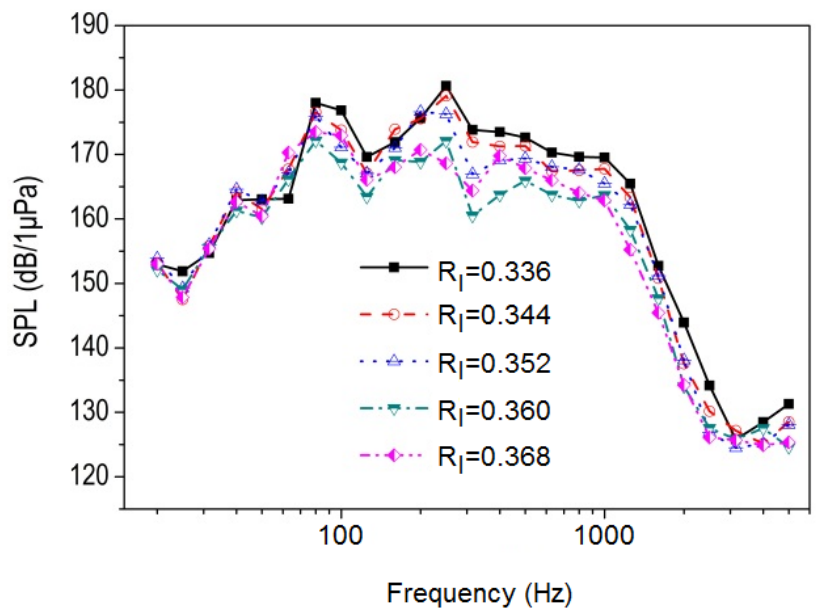

(c)

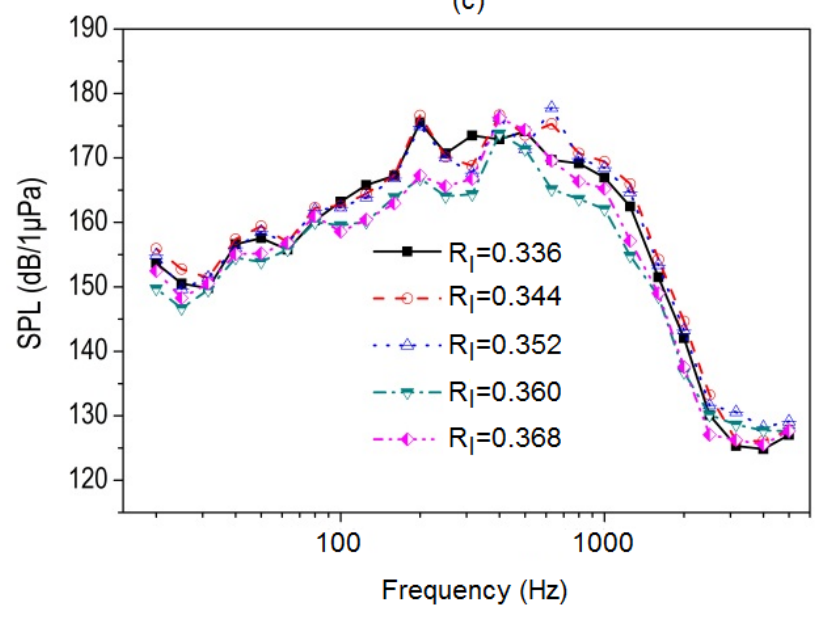

(e)

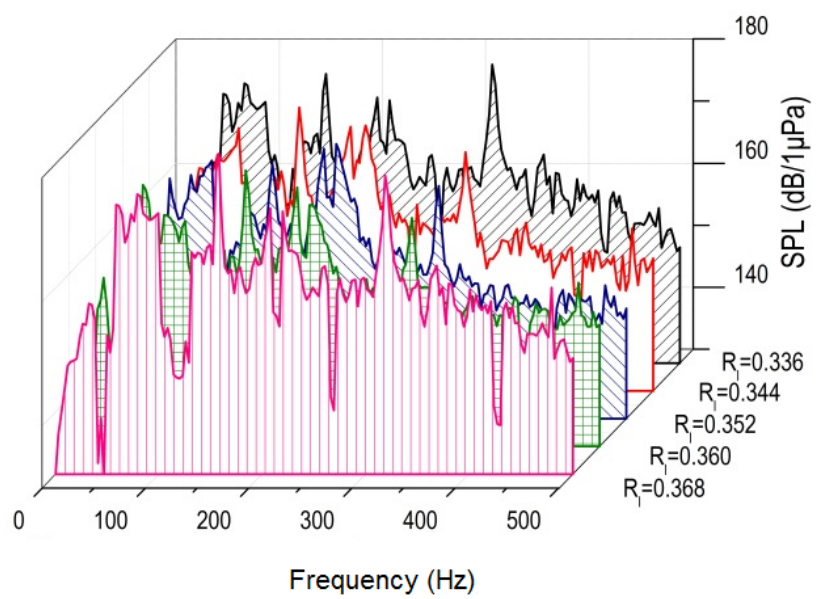

(b)

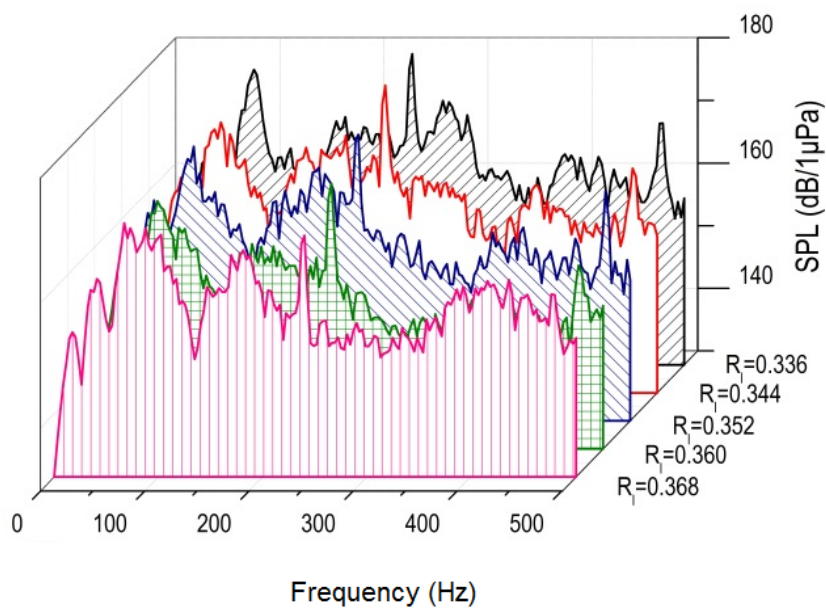

(d)

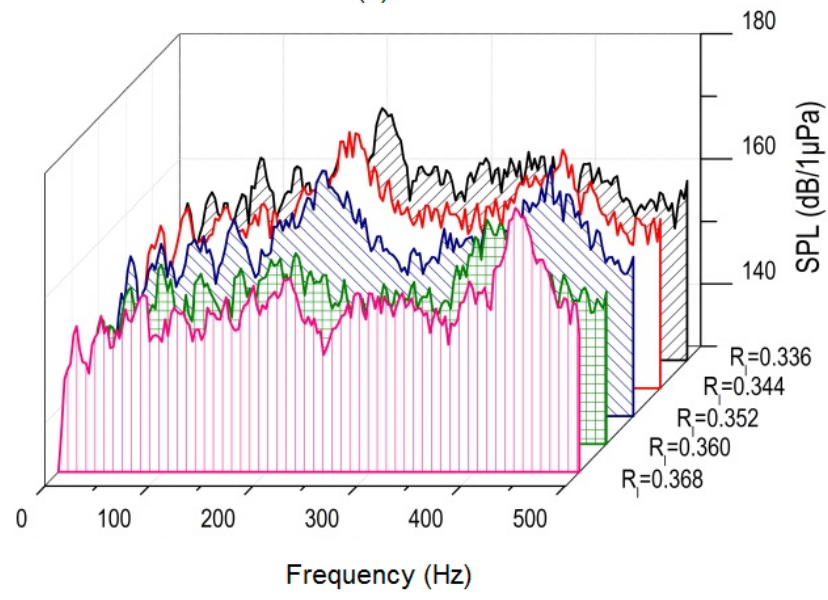

(f)

Figure 8. Comparison of the water mufflers with different inner structures at three different speeds: (a) $1172 \mathrm{r} / \mathrm{min}$ one-third octave spectrogram, (b) $1172 \mathrm{r} / \mathrm{min}$ frequency spectrogram, (c) $1758 \mathrm{r} / \mathrm{min}$ one-third octave spectrogram, (d) $1758 \mathrm{r} / \mathrm{min}$ frequency spectrogram, (e) $2344 \mathrm{r} / \mathrm{min}$ one-third octave spectrogram, (f) $2344 \mathrm{r} / \mathrm{min}$ frequency spectrogram.

$1.5 \times 106 \mathrm{~N} \cdot \frac{\mathrm{s}}{\mathrm{m}^{3}}$, which equals the characteristic impedance of water (density $=1000 \frac{\mathrm{kg}}{\mathrm{m}^{3}}$ and sound speed $\left.=1500 \frac{\mathrm{m}}{\mathrm{s}^{2}}\right)$.

\subsection{Computational Results}

Acoustic performances of the rubber tube and the water muffler with $R_{l}=0.336$ at the three speeds and the mufflers with different inner structures at the speed of $1172 \mathrm{r} / \mathrm{min}$ were evaluated by the above simulation method, in which the water flow was not included.

The simulation and experimental results of the rubber tube and the water muffler with $R_{l}=0.336$ are shown in Fig. 11. At the speed of $1172 \mathrm{r} / \mathrm{min}$, discrepancies between the two sets of results were less than $5 \%$ except for some specific frequencies, where the maximum discrepancy can be as large as $10 \%$. This was believed to be associated with the system simplification 


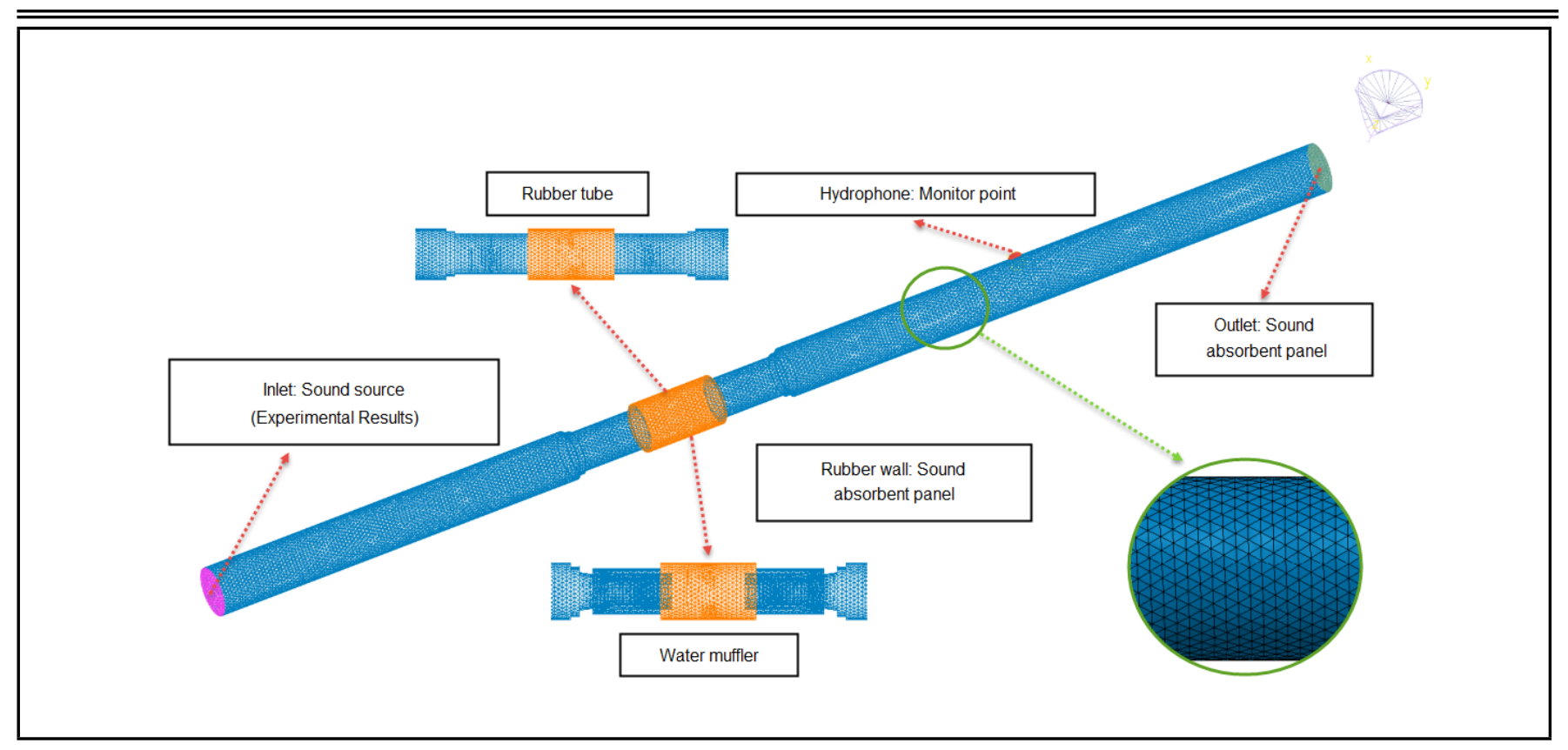

Figure 9. Schematic of the computation grid.

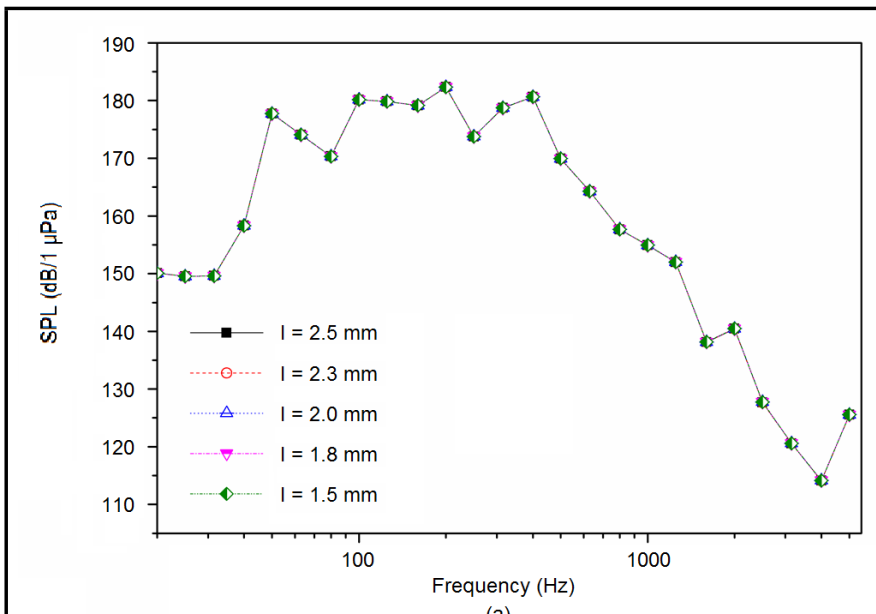

(a)

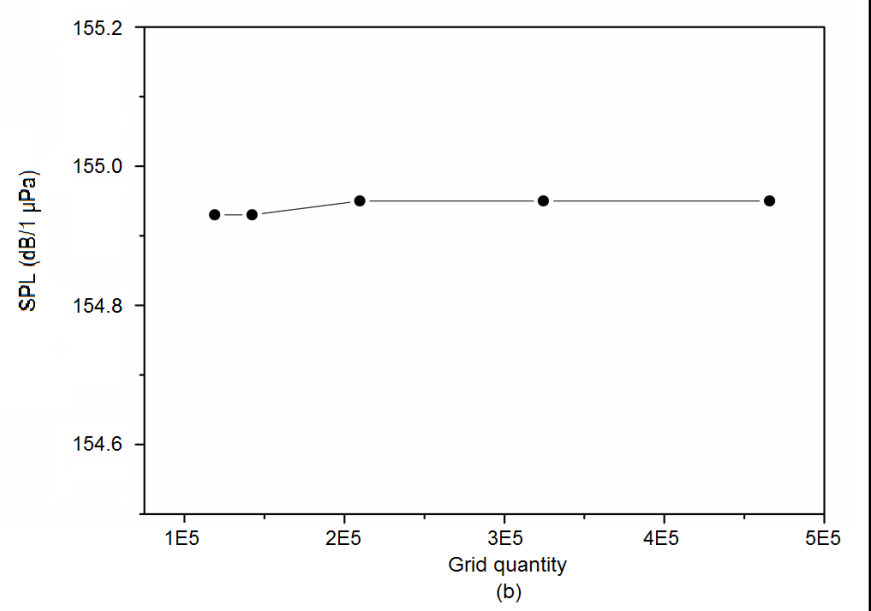

Figure 10. Results of grid independence test: (a) $20 \sim 5000 \mathrm{~Hz} S P L$ computed with various grid sizes, (b) $1000 \mathrm{~Hz} S P L$ computed with various grid quantities..

and the sound source model with inadequate accuracy in numerical simulations. However, the good accordance of general tendency between the simulation and experimental results was still seen, and the noise reduction of the proposed water muffler can be validated from both numerical and experimental approaches. The experimental results were also found to be increasingly greater from the simulation result as the speed grew, especially in the case of rubber tube. This was believed to be attributed to the flow-induced noise increased with flow velocity, as mentioned previously.

Simulation results of water mufflers with different inner structures at the speed of $1172 \mathrm{r} / \mathrm{min}$ are plotted in Fig. 12. It can be seen from the figure, the length of the inner structure do not significantly impact the acoustic performances of water mufflers, since the largest variation of $2.1 \mathrm{~dB}$ could be found at $2500 \mathrm{~Hz}$, as shown in Fig. 11. However, it can still be told from such a trivial variation that the increase of $R_{l}$ leads to the decrease of $S P L$. Since the effect of the flow is not included in the simulation, the discrepancy between the simulation and experimental results was considered to be the result of the flow-induced noise in the practical application.

\section{CONCLUSIONS}

A water muffler is used in the noise control for pipeline with an external gear pump. An experimental system is established to investigate the acoustic performance of the water muffler in which a gear pump is employed as the sound source and power supply. Numerical simulations of the rubber tube and water mufflers with different inner structures have been conducted in commercial software. From the comparison of the experimental results and the simulation results, the main conclusions are as follows:

The rubber tube with a compliant wall substantially contributes to the reduction of the noise generated by the gear pump, especially at the high frequency band and relatively low speed; while the water muffler obviously results in the enhancement of the noise reduction effect. This is attributed to the sound reflection at the inner structure and its effect in reducing the fluid pulsation.

With the speed of the gear pump increasing from $1172 \mathrm{r} / \mathrm{min}$ to $2344 \mathrm{r} / \mathrm{min}$, the noise reduction effect becomes weaker as the flow-induced noise gets intensified, especially for the rub- 


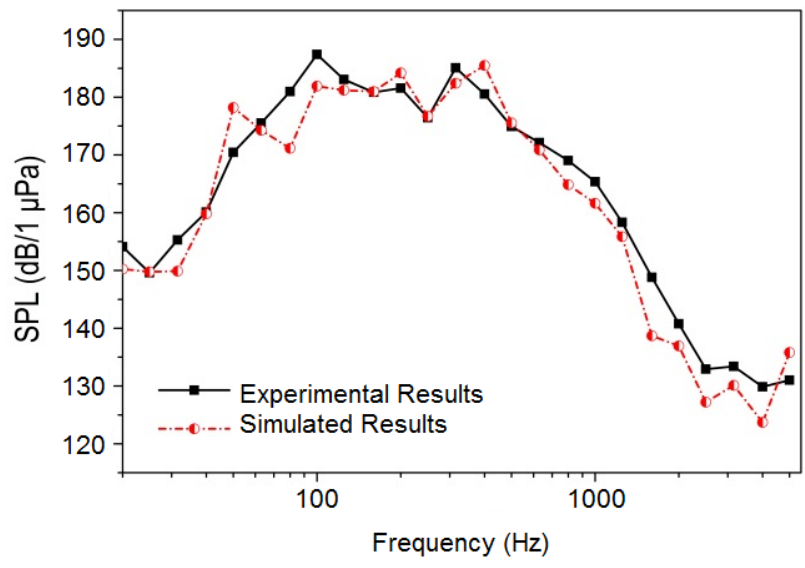

(a)

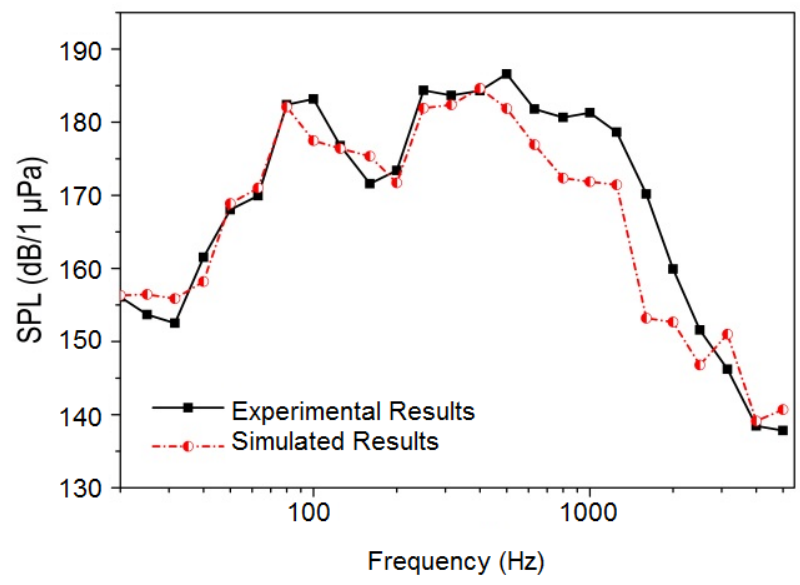

(c)

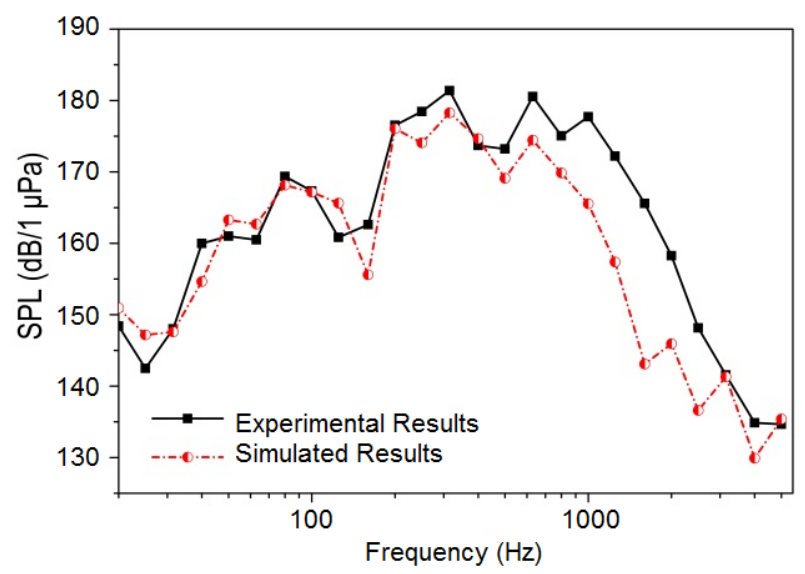

(e)

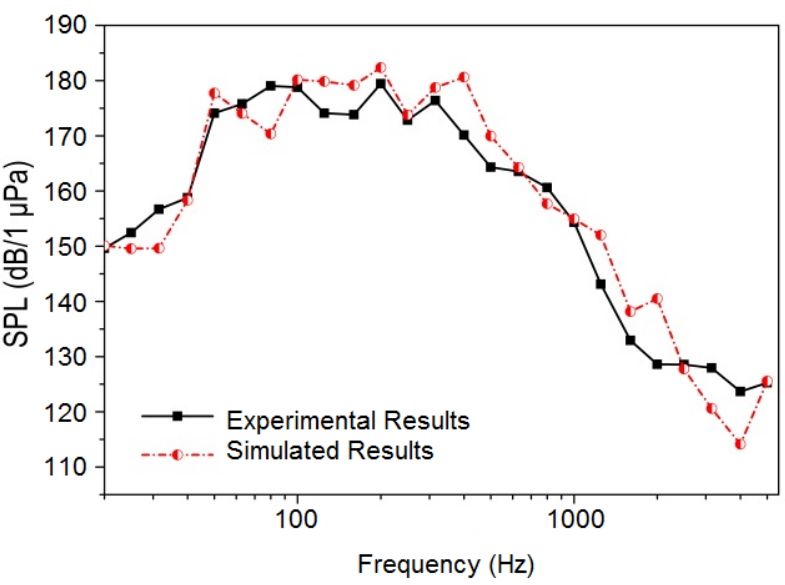

(b)

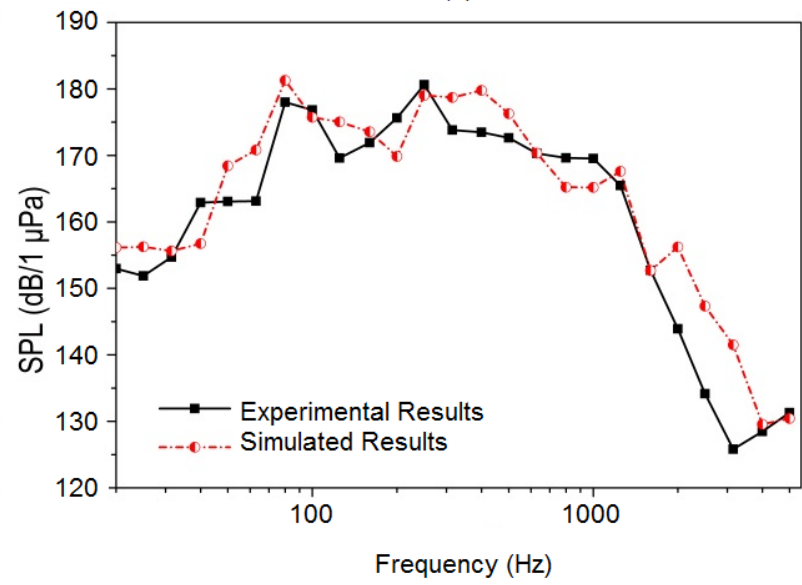

(d)

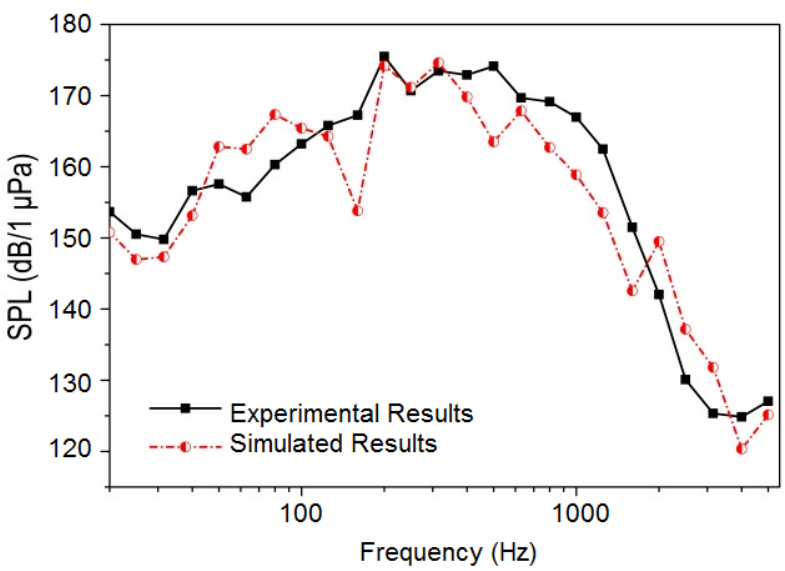

(f)

Figure 11. Comparison between experimental and simulation results at three speeds: (a) $1172 \mathrm{r} / \mathrm{min}$ Rubber tube, (b) $1172 \mathrm{r} / \mathrm{min}$ Water muffler, (c) $1758 \mathrm{r} / \mathrm{min}$ Rubber tube, (d) $1758 \mathrm{r} / \mathrm{min}$ Water muffler, (e) $2344 \mathrm{r} / \mathrm{min}$ Rubber tube, (f) $2344 \mathrm{r} / \mathrm{min}$ Water muffler.

ber tube in which the sound pressure level turns to be close to that of the reference tube at the speed of $2344 \mathrm{r} / \mathrm{min}$.

In both the simulation and the theoretical results, the water mufflers with different inner structures cannot significantly distinguish from each other in the noise reduction effects, since they only show slight difference in the inner structure length. A relatively larger difference could be found in the experimental results, which are considered as the result of the flow-induced noise. In general, the water mufflers with $R_{l}$ of 0.360 and 0.368 have better performances.

\section{ACKNOWLEDGEMENTS}

The authors would like to thank the financial support of National Nature Science Foundation of China (No. 51276213).

\section{REFERENCES}

1 Huang, K. J. and Lian, W. C. Kinematic flow rate characteristics of external spur gear pumps usingan exact closed solution, Mechanism and Machine Theory, 44 (6), 1121-1131, (2009). https://dx.doi.org/10.1016/j.mechmachtheory.2008.10.002 
Table 3. Impedances of the rubber wall.

\begin{tabular}{|c|c|c|}
\hline & \multicolumn{2}{|c|}{ Rubber Wall $\left(\mathrm{kg} /\left(\mathrm{m}^{2} \cdot \mathrm{s}\right)\right)$} \\
\hline Frequency (Hz) & Real & Imaginary \\
\hline 20 & $3,000,000$ & $3,000,000$ \\
\hline 25 & $3,000,000$ & $3,000,000$ \\
\hline 31.5 & $3,000,000$ & $3,000,000$ \\
\hline 40 & 400,000 & 400,000 \\
\hline 50 & $3,000,000$ & $3,000,000$ \\
\hline 63 & $30,000,000$ & $30,000,000$ \\
\hline 80 & $3,000,000$ & $3,000,000$ \\
\hline 100 & $1,000,000$ & $1,000,000$ \\
\hline 125 & $3,000,000$ & $3,000,000$ \\
\hline 160 & $3,000,000$ & $3,000,000$ \\
\hline 200 & $9,000,000$ & $9,000,000$ \\
\hline 250 & $3,000,000$ & $3,000,000$ \\
\hline 315 & $3,000,000$ & $3,000,000$ \\
\hline 400 & $8,000,000$ & $8,000,000$ \\
\hline 500 & $3,000,000$ & $3,000,000$ \\
\hline 630 & $3,000,000$ & $3,000,000$ \\
\hline 800 & $2,000,000$ & $2,000,000$ \\
\hline 1000 & $1,800,000$ & $1,800,000$ \\
\hline 1250 & $2,800,000$ & $2,800,000$ \\
\hline 1600 & $1,000,000$ & $1,000,000$ \\
\hline 2000 & $2,200,000$ & $2,200,000$ \\
\hline 2500 & 400,000 & 400,000 \\
\hline 3150 & $8,500,000$ & $8,500,000$ \\
\hline 4000 & $4,500,000$ & $4,500,000$ \\
\hline 5000 & $9,500,000$ & $9,500,000$ \\
\hline & & \\
\hline & & \\
\hline & &
\end{tabular}

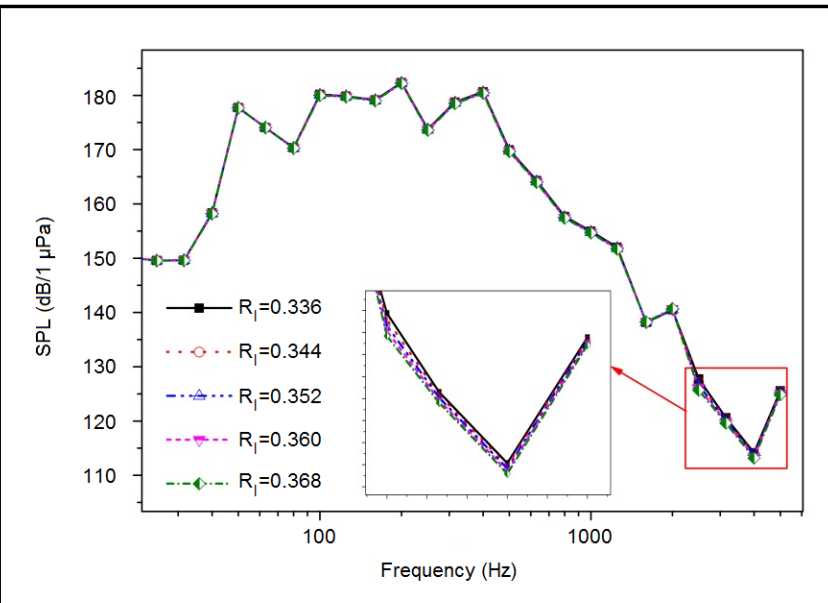

Figure 12. Simulation results of water mufflers with different inner structures.

2 Manring, N. D. and Kasaragadda, S. B. The theoretical flow ripple of an external gear pump, Journal of Dynamic Systems, Measurement, and Control, 125 (3), 396-404, (2003). https://dx.doi.org/10.1115/1.1592193

3 Mucchi, E., Dalpiaz, G., and del Rincòn, A. F. Elastodynamic analysis of a gear pump. Part I: Pressure distribution and gear eccentricity, Mechanical Systems and Signal Processing, 24 (7), 2160-2179, (2010). https://dx.doi.org/10.1016/j.ymssp.2010.02.003

4 Mucchi, E., Dalpiaz, G., and Rivola, A. Elastodynamic analysis of a gear pump. Part II: Meshing phenomena and simulation results, Mechanical Systems and Signal Processing, 24 (7), 2180-2197, (2010). https://dx.doi.org/10.1016/j.ymssp.2010.02.004

5 Foster, K., Taylor, R., and Bidhendi, I. M. Computer prediction of cyclic excitation sources for an external gear pump, Proceedings of the Institution of Mechanical Engineers, Part B: Journal of En- gineering Manufacture, 199 (3), 175-180, (1985) https://dx.doi.org/10.1243/PIME_PROC_1985_199_064_02

${ }^{6}$ Iyoi, H. and Ishimura, S. X-theory in gear geometry, Transactions of the ASME: Journal of Mechanisms, Transmissions, and Automation in Design, 105 (3), 286-290, (1983). https://dx.doi.org/10.1115/1.3267358

7 Mitome, K. and Seki, K. A new continuous contact lownoise gear pump, Journal of Mechanical Design, 105 (4), 736-741, (1983). https://dx.doi.org/10.1115/1.3258544

8 Strunk, R. D. Silencer for hydraulic piston pump pressure pulsations, SAE Transactions, 100 (2), 135-141, (1991). https://dx.doi.org/10.4271/911759

9 Dodson, J. M., Dowling, D. R., and Grosh, K. Experimental investigation of quarter wavelength silencers in large-scale hydraulic systems, Noise Control Engineering Journal, 46 (1), 15-22, (1998).

10 Kojima, E. and Ichiyanagi, T. Development research of new types of multiple volume resonators, Bath Workshop on Power Transmission and Motion Control, Bath, England, (1998).

11 Mikota, J. A novel, compact pulsation compensator to reduce pressure pulsations in hydraulic systems, World Scientific, 45, 69-78, (2001).

12 Earnhart, N. E. and Cunefare, K. A. Compact helmholtz resonators for hydraulic systems, International Journal of Fluid Power, 13 (1), 41-50, (2012). https://dx.doi.org/10.1080/14399776.2012.10781045

13 Du, T., Li, S. Y., Liu, J. T., and Wu, D. Z. Acoustic performance of a water muffler, Noise control engineering journal, 63 (3), 239-248, (2015). https://dx.doi.org/10.3397/1/376322

14 Munjal, M. L. Acoustics of ducts and mufflers with application to exhaust and ventilation system design, John Wiley \& Sons, New York, (1987).

15 Selamet, A., Kothamasu, V., and Novak, J. M. Insertion loss of a helmholtz resonator in the intake system of internal combustion engines: an experimental and computational investigation, Applied Acoustics, 62 (4), 381-409, (2001). https://dx.doi.org/10.1016/S0003-682X(00)00042-6

16 Koussa, F., Defrance, J., Jean, P., and BlancBenon, P. Acoustic performance of gabions noise barriers: Numerical and experimental approaches, Applied Acoustics, 74 (1), 189-197, (2013). https://dx.doi.org/10.1016/j.apacoust.2012.07.009

17 Lee, Y. Y. and Cheng G. F. Insertion loss of a cavitybacked semi-cylindrical enclosure panel, Journal of Sound and Vibration, 259 (3), 625-636, (2003). https://dx.doi.org/10.1006/jsvi.2002.5096

18 Pfretzschner, J. and Rodriguez, R. M. Acoustic properties of rubber crumbs, Polymer Testing, 18 (2), 81-92, (1999). https://dx.doi.org/10.1016/S0142-9418(98)00009-9 